\title{
Imported Plasmodium vivax malaria with severe thrombocytopaenia: can it be severe malaria or not?
}

\author{
Spinello Antinori ${ }^{1 *}$, Alberto Corona ${ }^{2}$, Anna Lisa Ridolfo ${ }^{1}$, Laura Galimberti ${ }^{1}$, Davide Ricaboni ${ }^{1}$, Laura Milazzo \\ and Mario Corbellino ${ }^{1}$
}

\begin{abstract}
Background: Thrombocytopaenia is the most frequent malaria-associated haematologic alteration observed with all five Plasmodium parasites causing disease in humans. Although not included in the World Health Organization criteria for severe Plasmodium falciparum malaria, severe thrombocytopaenia has been increasingly mentioned as an indicator of P. vivax malaria severity.

Case: Here, it is described a case of imported $P$. vivax malaria in a 37-year old man from Pakistan who presented with severe thrombocytopaenia $\left(5 \times 10^{9} / \mathrm{L}\right)$. He was admitted to the intensive care unit and initially treated with a 1-day course of intravenous quinine followed by oral chloroquine and primaquine. The patient's platelet count increased as early as 4 hours after treatment inception and the clinical course was favourable and uneventful.

Discussion: This case report, along with a review of published cases focusing on the relationship between thrombocytopaenia and severe P. vivax malaria, suggests that the prognostic role of severe thrombocytopaenia is ambiguous in absence of severe haemorraghic complications and its use as diagnostic criterion of malaria severity may lead to overestimation of severe P. vivax malaria cases.
\end{abstract}

Conclusion: Due to the lack of high quality studies it is at present unclear if severe thrombocytopaenia in the setting of P. vivax malaria should be considered indicative of severe malaria.

Keywords: Plasmodium vivax, Severe thrombocytopaenia, Severe malaria, Imported malaria, Bleeding

\section{Background}

Plasmodium vivax is responsible for nearly half of all malaria cases diagnosed outside sub-Saharan Africa and it exhibits the widest geographical distribution of human malaria parasites with an estimated 2.49 billion individuals living in areas at risk of infection [1]. Plasmodium vivax malaria has been long known as "benign tertian malaria" as opposed to the "malignant tertian or subtertian malaria" caused by P. falciparum [2]. However, in recent years an increasing number of studies, especially from the Indian subcontinent and South America, have

\footnotetext{
*Correspondence: spinello.antinori@unimi.it

${ }^{1}$ Department of Clinical and Biomedical Sciences Luigi Sacco, III Division of Infectious Diseases, University of Milano, Via GB Grassi, 74, 20157 Milan, Italy

Full list of author information is available at the end of the article
}

highlighted the role of $P$. vivax as a cause of severe and even fatal malaria [3-7]. For this reason, Baird recommended, in his revision of the nomenclature of human malaria, to include vivax malaria as an "acute pernicious" entity in terms of clinical presentation and evolution [6].

However, conflicting issues emerge from cases of severe $P$. vivax malaria that are increasingly reported in the literature, partly because of the lack of a clear definition of the severity criteria, and partly from the possible interference of concomitant morbidities and infections on the clinical presentation and outcome [8].

Low platelet counts are commonly encountered in all types of malaria, and values lower than $60,000 / \mu \mathrm{L}$ have been reported in $29-46 \%$ of patients affected with vivax malaria $[9,10]$. However, thrombocytopaenia is not regarded as a severity biomarker in falciparum malaria, 
and it has not as yet been validated as an independent severity parameter in vivax malaria. Of note, in several studies and case reports, severe thrombocytopaenia was described as the most prevalent severity sign of vivax malaria [11-15]. Therefore, it cannot be excluded that the use of such an indicator may lead to an overestimation of $P$. vivax malaria severity.

Here, it is described a case of imported $P$. vivax malaria characterized by severe thrombocytopaenia along with a review of similar cases reported in the literature. Furthermore, it is discussed whether severe thrombocytopaenia should be considered a reliable biomarker of $P$. vivax malaria severity.

\section{Case report}

A 37-year old male from Pakistan arrived in Italy in July 2013 to attend a professional course. After few days, he developed high grade fever $\left(40^{\circ} \mathrm{C}\right)$ associated with chills, headache and one episode of vomiting. He was visited by a primary physician who prescribed him cefixime $400 \mathrm{mg} /$ day and acetaminophen. After 4 days, due to the persistence of fever and the onset of productive cough and asthenia, cefixime was changed to levofloxacin $(500 \mathrm{mg} /$ day). However, the fever did not resolve, and therefore the patient was taken to the nearest emergency department (ED). At presentation, he was febrile $\left(39.5^{\circ} \mathrm{C}\right)$, tachycardic (121 beats per $\mathrm{min}$ ) and hypotensive $(90 / 50 \mathrm{~mm} \mathrm{Hg}$ ); there were no meningeal signs and the Glasgow Coma Score was normal (15). Oxygen saturation while breathing ambient air was $99 \%$, the respiratory examination and a chest radiograph were both normal. Laboratory investigations were as follows: haemoglobin, $15.9 \mathrm{~g} / \mathrm{dL}$; red blood cell count, $5.54 \times 10^{9} / \mathrm{L}$; total white cell count, $6.3 \times 10^{9} / \mathrm{L}$ (with $85 \%$ neutrophils, $11 \%$ lymphocytes and $4 \%$ monocytes); platelet count, $14 \times 10^{9} / \mathrm{L}$. With the exception of D-dimer concentration ( $9376 \mathrm{ng} / \mathrm{dL})$, the other coagulation parameters were within the normal range. Hyponatremia $(127 \mathrm{mmol} / \mathrm{L})$ was present as well as raised values of $C$ reactive protein $(126 \mathrm{mg} / \mathrm{L})$, total bilirubin $(3.3 \mathrm{mg} /$ $\mathrm{dL})$, and lactate dehydrogenase (371 U/L). Serum concentrations of glucose, liver enzymes, urea and creatinine were within normal ranges. An ultrasound scan of the abdomen showed no hepatosplenomegaly and a normal biliary tract. Legionella and pneumococcus urine antigens were negative. A thin blood film showed "malaria parasites" that were not identified at the species level by the laboratory technician. Due to lack of anti-malarial drugs and the expertise for the diagnosis and therapy of malaria, the ED physician contacted the Luigi Sacco hospital in Milan for assistance. Ten hours after presentation at the first ED, the patient was finally admitted to the intensive care unit of Luigi Sacco hospital with a provisional diagnosis of "severe malaria", based on the results of the laboratory tests (severe thrombocytopaenia and raised bilirubin levels) and the presence of hypotension. On physical examination, when admitted to the ICU, the patient was conscious, fully oriented to time and place with high fever $\left(40{ }^{\circ} \mathrm{C}\right)$ and had severe headache. The pulmonary, cardiovascular and abdominal examinations were reportedly unremarkable. Neither signs of bleeding nor skin petechiae were detected. No previous history of malaria episodes was elicited and no underlying chronic diseases were present. The patient was treated with a loading dose of intravenous quinine (1200 mg). At treatment inception the platelet count was $5 \times 10^{9} / \mathrm{L}$, without haemorrhagic manifestations. Examination of the peripheral blood smear by the haematologist did not reveal platelet clumping and a blood sample obtained with sodium citrate confirmed the finding of low platelet counts thus excluding a diagnosis of pseudothrombocytopaenia. In the absence of bleeding the haematologist judged as unnecessary the use of platelet transfusions. Thick and thin blood smear examinations were diagnostic for $P$. vivax infection with schizonts, gametocytes and ring forms being detected and a very low parasitaemia (0.1\%). Plasmodium vivax monoinfection was subsequently confirmed by DNA polymerase chain reaction performed on a stored blood sample obtained on admission. Blood and urine cultures were obtained but gave negative results. Serology for HIV, CMV, dengue virus, leptospirosis, syphilis, Brucella and typhoid fever were negative.

Platelet counts showed a rapid increase soon after the infusion of quinine (i.e., $13 \times 10^{9} / \mathrm{L}, 16 \times 10^{9} / \mathrm{L}$, $20 \times 10^{9} / \mathrm{L}, 32 \times 10^{9} / \mathrm{L}$, respectively, after $4,10,18$ and $24 \mathrm{~h})$. The following morning an infectious diseases consultation was requested which suggested an interruption of intravenous quinine (after two doses administered). In consideration of the stable clinical condition and the diagnosis of $P$. vivax malaria the patient was transferred to the Infectious Diseases ward where oral chloroquine was started to complete the treatment. Parasite clearance was observed within $48 \mathrm{~h}$ after hospital admission as well as improvement or complete disappearance of all accompanying signs and symptoms (fever, headache, nausea, asthenia, myalgia). After completing a 3-day course of chloroquine treatment, and documentation of normal glucose 6-phosphate dehydrogenase activity levels, the patient was started on oral primaquine (15 $\mathrm{mg}$ of base in a $26.3 \mathrm{mg}$ tablet per day for 14 days) and discharged the fifth day of hospitalization in good clinical conditions and with platelet counts within the normal range $\left(223 \times 10^{9} / \mathrm{L}\right)$.

\section{Discussion}

In this case report, a man from Pakistan with imported $P$. vivax malaria was initially classified as affected by severe 
malaria and admitted to the ICU on the basis of profound thrombocytopaenia. Despite the initial presentation, the patient's clinical course was uneventful and the platelet counts recovered very rapidly under anti-malarial treatment [16]. In recent years, an increasing number of case reports and hospital-based studies, have questioned the notion of "benign tertian malaria" by describing severe and even fatal malaria associated with $P$. vivax infection [3-8, 12-15]. In many instances, severe thrombocytopaenia was used by the authors of these reports as the stand-alone criterion of malaria severity, irrespective of the presence of haemorrhagic events and/or other signs of disease severity.

However, two relevant aspects deserve to be considered when interpreting the findings of these studies. The first concerns the lack of any specific case definition for severe $P$. vivax malaria and, consequently, the question of whether severe thrombocytopaenia should be considered, in the absence of bleeding, a marker of disease severity.

Thrombocytopaenia (i.e., a platelet count below $150,000 / \mu \mathrm{L})$ is a frequent haematological finding in all types of malaria and it is observed in $29-93.3 \%$ of patients with $P$. vivax malaria $[9,17]$. The exact mechanisms underlying the decrease in platelet counts is still unknown, but various hypothesis have been advanced including immune-mediated phenomena, oxidative stress, alterations in splenic function and a direct interaction between the parasite and platelets [18-22]. Recently, Coelho and coworkers demonstrated that macrophagedriven phagocytosis of platelets may be an important contributory mechanism and that the mean platelet volume was greater in thrombocytopaenic patients with vivax malaria than in controls [23]. The latter finding is particularly interesting because the presence of large circulating platelets and may be viewed as compensatory mechanism in order to preserve primary haemostasis. Accordingly, bleeding is seldomly observed in the course of malaria even among patients with severe thrombocytopaenia. So what is the clinical and prognostic significance of severe thrombocytopaenia in patients with vivax malaria?

Thirty-three case reports of severe thrombocytopaenia (median platelet count: $21,000 / \mu \mathrm{L}$, range: $2000-45,000 /$ $\mu \mathrm{L})$ in patients with vivax malaria have been published in the medical literature from 1993 to 2014 (the majority after 2006) $[11,12,15,24-51]$. Ten individuals presented with haemorrhagic manifestations $[27,28,30,35$, $38,40,41,43,48]$ and nine received platelet transfusions: all patients recovered with the exception of one who died because of shock and pancreatitis [45] (Table 1).

Information regarding the relationship between vivax malaria and thrombocytopaenia adopted as a criterion for assessing malaria severity may be also extracted from 17 clinical studies (13 from India [13, 14, 52-62], two from Pakistan $[63,64]$ and one each from Colombia and Sudan $[65,66])$. In fifteen of these studies, a cutoff value of less than 50,000 platelets per $\mu \mathrm{L}$ was used to define severe thrombocytopaenia [13, 52-60, 62-66]. Overall, platelet counts below $50,000 / \mu \mathrm{L}$ were present in 335 out of the 906 cases of severe malaria examined (36.9\%), although the prevalence varied significantly among the studies, from $12.5 \%$ to $93 \%$ (Table 2), because of the different selection criteria employed. Bleeding manifestations (mainly epistaxis) were observed in 108 patients (34.8\%), but only in two patients were they serious enough to directly contribute to death (i.e., disseminated intravascular coagulation and gastrointestinal tract haemorrhage) [54, 58].

It is noteworthy that mixed $P$. vivax and $P$. falciparum infections were not ruled out in 14 out of 17 studies [14, 52, 53, 63-66]. In addition, coexisting infections that may contribute to thrombocytopaenia (such as dengue fever, leptospirosis or bacterial sepsis) were not excluded in the majority of the studies [14, 52-55, 57, 58, 60-66]. Regarding the latter issue, a recent study conducted in the Brazilian Amazon showed that $17.6 \%$ of patients with $P$. vivax malaria had concomitant dengue infection and these had a higher probability to present with haemorrhagic manifestations and jaundice [67].

Other studies have focused on the prognostic role of thrombocytopaenia in vivax malaria. Leal-Santos and coworkers in a cross-sectional study conducted in 186 patients from the Mato Grosso region showed that mean platelet volume and platelet distribution width (PDW) were significantly associated with the presence of warning signs of severe and complicated malaria (i.e., anaemia, hypotension and elevated creatinine levels) with odds ratios (OR) of 3.47 and 5.44, respectively [68]. In keeping with the above mentioned results, a large study conducted in Papua New Guinea showed that the greatest risk of severe thrombocytopaenia was associated with $P$. falciparum malaria (OR 6.03 vs 3.73 for $P$. vivax). However, the mortality risk for patients with severe thrombocytopaenia was higher among patients without malaria $(7.9 \%)$ than among those with $P$. falciparum $(2.1 \%)$ or P. vivax (1.5\%) malaria [69]. The authors also found a 16 -fold higher risk of death when severe thrombocytopaenia was associated with severe anaemia (haemoglobin concentration below $5 \mathrm{mg} / \mathrm{dL}$ ), and concluded that severe thrombocytopaenia should serve as a warning sign of poor outcome in patients with malaria particularly when it is accompanied by severe anaemia. Based on their findings, Lampah and coworkers proposed a threshold of $\leq 20,000$ platelets $/ \mu \mathrm{L}$ as a defining severity criterion for both $P$. falciparum and $P$. vivax malaria [69]. 


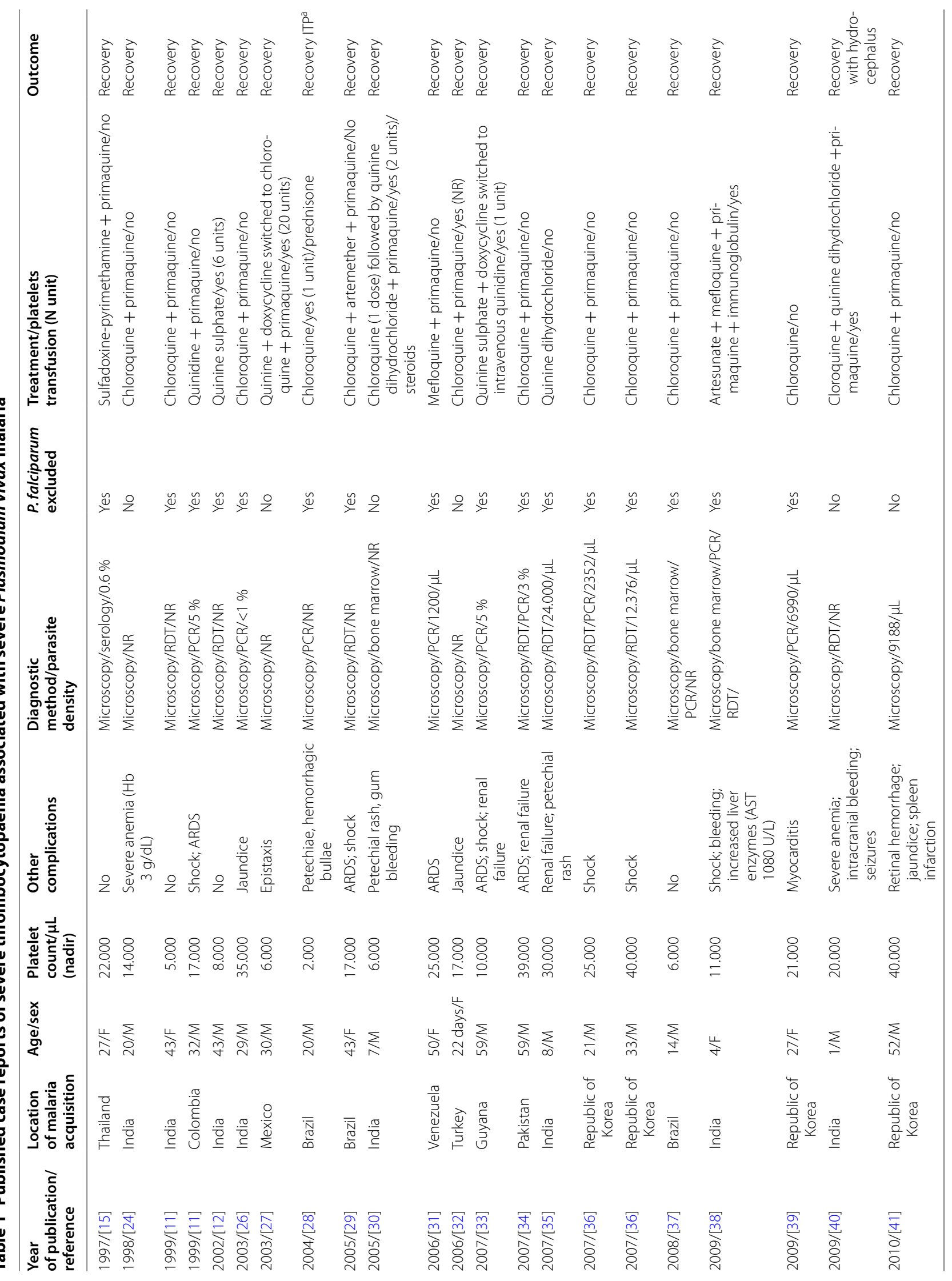




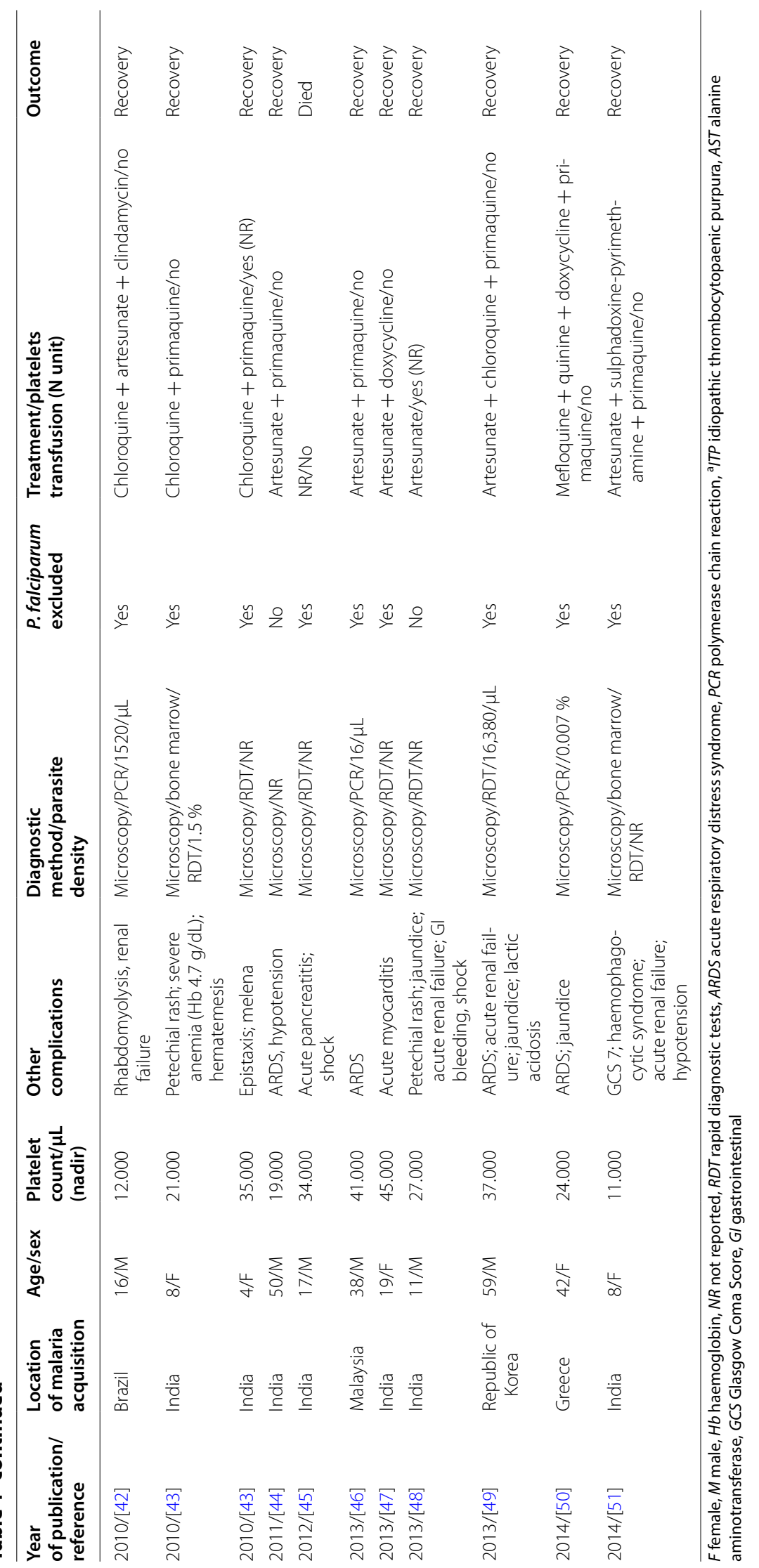




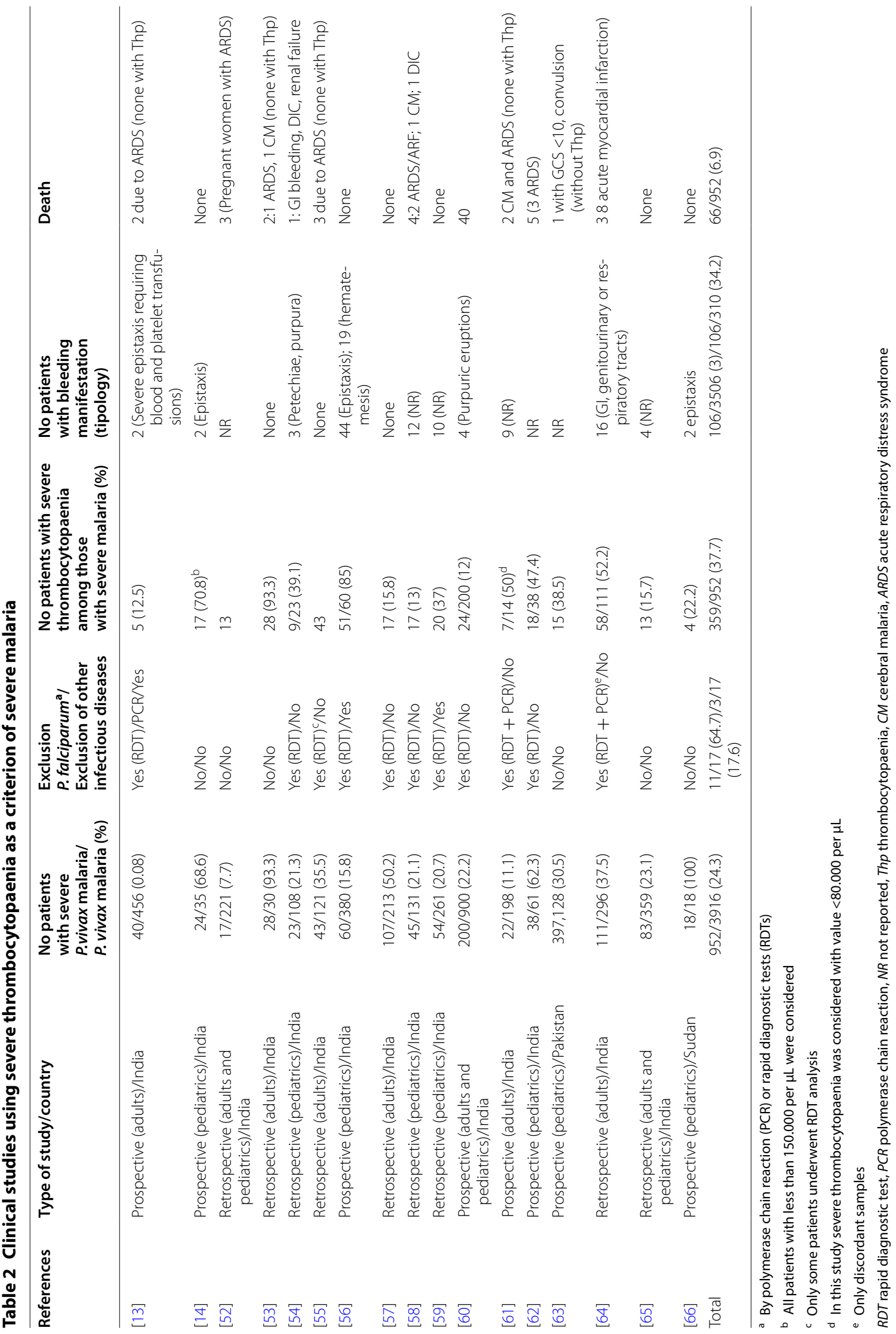


However, in a recent study conducted in Brazil and India on 778 patients with documented $P$. vivax monoinfection, platelet counts showed a very poor discriminative performance to identify criteria of severe disease and the authors concluded that thrombocytopaenia should not be used to identify patients with $P$. vivax complications [70].

The second issue that deserves to be addressed when considering disease severity regards mortality. In other words: did patients whose death was attributed to $P$. vivax malaria die of malaria or with malaria?

This issue has been addressed in one study only which was conducted in Brazil and reported the autopsy findings of 17 patients who died of $P$. vivax malaria [5]. The authors reported during the study period (1996-2010) a case-fatality rate (CFR) for P. vivax malaria of $0.011 \%$ $(19 / 170.286)$, but in only four of the seventeen patients who underwent autopsy death could be exclusively attributed to $P$. vivax malaria, resulting in a CFR of $0.002 \%$ [5]. Of note, the CFR of $P$. vivax malaria was 16-fold lower than the one observed for $P$. falciparum malaria in the same period $(0.032 \%, 12 / 36.854)$ [5]. In another study conducted in Papua, Indonesia, between January 2004 and September 2009, a post hoc clinical death audit of cases of pure $P$. vivax malaria resulted in a CFR of 0.12 per 1000 infections [71]. Of note, of the six fatal cases for whom vivax malaria was considered the primary cause of death, four were young children of less than 2 years of age (two of whom were malnourished), and the other two were adults in whom sepsis was concomitantly documented.

Moreover, in a retrospective analysis of 12.769 cases of imported $P$. vivax malaria observed in the UK over 27 years (1987-2013), seven deaths were registered, giving an overall mortality of $0.05 \%$. The median age of deceased patients was 72 years, while no deaths occurred in the 9927 patients aged less than 50 years [72]. In the two studies regarding imported $P$. vivax malaria conducted by the TropNetEurope and the GeoSentinel network, reporting respectively 618 and 278 patients (either travellers or immigrants), no deaths were recorded among patients affected by this species of Plasmodium $[73,74]$.

Thus, based on available data, the mortality risk of $P$. vivax malaria seems to be different in endemic areas as opposed to what is observed in cases of imported disease in Europe or USA. In endemic areas, the risk of death is low and influenced by several factors, such as very young age, severe anaemia at presentation, malnutrition, pregnancy, coexisting comorbidities and concurrent infections [69-71, 75]. When imported P. vivax malaria is considered, the risk of death is generally absent or negligible and principally influenced by old age. Another important issue that should be considered when comparing malaria mortality is the lack of high level supportive care in many countries where malaria is endemic a factor that explains the better outcome observed in non-endemic countries where high-quality healthcare is available [76]. Despite these considerations it should be emphasized that the risk of death directly attributable to $P$. vivax malaria should not be overlooked.

In conclusion, given the lack of high quality studies and the fact that several confounding factors cannot be ruled out in the majority of case reports and studies published so far, the role of severe thrombocytopaenia as an indicator of $P$. vivax malaria severity cannot at present neither be discarded nor confirmed and it deserves to be addressed in well conducted prospective studies in both endemic and non-endemic countries.

\section{Abbreviations}

ED: emergency department; WHO: World Health Organization; ICU: intensive care unit; G6PD: glucose-6-phosphate dehydrogenase; PCR: polymerase chain reaction; CFR: case-fatality rate; DIC: disseminated intravascular coagulation.

\section{Authors' contributions}

All authors contributed to the content of this case report. SA performed the clinical assessments, data collection and drafted the manuscript. AC treated the patient in the ICU. AL R and LM searched the literature and drafted manuscript LG treated the patient until discharge and drafted the manuscript. MC performed the clinical assessments and drafted the manuscript. DR performed the molecular diagnostic and drafted the manuscript. All authors read and approved the final manuscript.

\section{Author details}

${ }^{1}$ Department of Clinical and Biomedical Sciences Luigi Sacco, III Division of Infectious Diseases, University of Milano, Via GB Grassi, 74, 20157 Milan, Italy. ${ }^{2}$ Intensive Care Unit Luigi Sacco Hospital, Milan, Italy.

\section{Consent for publication}

Written informed consent was obtained from the patient for publication of this case report and any accompanying images.

\section{Competing interests}

The authors declare that they have no competing interests.

Received: 17 September 2015 Accepted: 4 February 2016

Published online: 19 February 2016

\section{References}

1. Gething PW, Elyazar IRF, Moyes CM, Smith DL, Battle KE, Guerra CA, et al. A long neglected world malaria map: Plasmodium vivax endemicity in 2010. PLoS Negl Trop Dis. 2012;6:e1814.

2. Marchiafava E, Bignami A. Mannaberg J. Two monographs on malaria and the parasites of malarial fevers. London: New Sydenham Society; 1894.

3. Nurleila S, Syafruddin D, Elyazar IRF, Baird JK. Serious and fatal illness associated with falciparum and vivax malaria among patients admitted to hospital at West Sumba in eastern Indonesia. Am J Trop Med Hyg. 2012;87:41-9

4. Alexandre MA, Ferreira CO, Siqueira AM, Magalhaes BL, Mourao MP, Lacerda MV, et al. Severe Plasmodium vivax malaria, Brazilian Amazon. Emerg Infect Dis. 2010;16:1611-4.

5. Lacerda MV, Fragoso SC, Alecrim MG, Alexandre MA, Magalhaes BM, Siqueira AM, et al. Postmortem characterization of patients with clinical diagnosis of Plasmodium vivax malaria: to what extent does this parasite kill? Clin Infect Dis. 2012;55:e67-74. 
6. Baird JK. Evidence and implications of mortality associated with acute Plasmodium vivax malaria. Clin Microbiol Rev. 2013;26:36-57.

7. Naing C, Whittaker MA, Wai VN, Mak JW. Is Plasmodium vivax malaria a severe malaria?:a systematic review and meta-analysis. PLoS Neglect Trop Dis. 2014;8:e3071.

8. Antinori S, Milazzo L, Ridolfo AL, Galimberti L, Corbellino M. Severe Plasmodium vivax malaria: fact or fiction? Clin Infect Dis. 2012;55:1581-3. Erratum in: Clin Infect Dis. 2013;56:1196.

9. Antinori S, Galimberti L, Gianelli E, Morelli P, Radice A, Acquaviva V, et al. Thrombocytopenia and Plasmodium vivax malaria. Clin Infect Dis. 2005:41:1210-1.

10. Oh MD, Shin H, Shin D, Kim U, Lee S, Kim N, et al. Clinical features of vivax malaria. Am J Trop Med Hyg. 2001;65:143-6.

11. Kakar A, Bhoi S, Prakash V, Kakar S. Profound thrombocytopenia in Plasmodium vivax malaria. Diagn Microbiol Infect Dis. 1999;35:243-4.

12. Makkar RP, Mukhopadhyay S, Monga A, Gupta AK. Plasmodium vivax malaria presenting with severe thrombocytopenia. Braz J Infect Dis. 2002;6:263-5.

13. Kochar DK, Das A, Kochar SK, Saxena V, Sirohi P, Garg S, et al. Severe Plasmodium vivax malaria: a report of serial cases from Bikaner in Northwestern India. Am J Trop Med Hyg. 2009;80:194-8.

14. Kaushik JS, Gomber S, Dewan P. Clinical and epidemiological profiles of severe malaria in children from Delhi, India. J Health Popul Nutr. 2012;30:113-6.

15. Yamaguchi S, Kubota T, Yamagishi T, Okamoto K, Izumi T, Takada M, et al. Severe thrombocytopenia suggesting immunological mechanisms in two cases of vivax malaria. Am J Hematol. 1997;56:183-6.

16. Khattak AL, Ali W, Khan NA, Satti L, Idris M. Response of Plasmodium vivax malaria induced thrombocytopenia to antimalarial treatment. JAMCA. 2014;26:463-5.

17. Lacerda MV, Mourao MP, Coelho HC, Santos JB. Thrombocytopenia in malaria: who cares? Mem Inst Oswaldo Cruz. 2011;106(Suppl 1):52-63.

18. Skudowitz RB, Katz J, Lurie A, Levin J, Metz J. Mechanisms of thrombocytopenia in malignant tertian malaria. BMJ. 1973;2:515-8.

19. Touze JE, Mercier P, Rogier C, Hovette P, Schmoor P, Dabanian C, et al. [Platelet antibody activity in malaria thrombocytopenia](in French). Pathol Biol. 1990;38:678-81.

20. Kelton JG, Keystone J, Moore J, Denomme G, Tozman E, Glynn M, et al. Immune-mediated thrombocytopenia of malaria. J Clin Invest. 1983;71:832-6.

21. Lee SH, Looareesuwan S, Chan J, Wilairatana P, Vanijanonta S, Chong $\mathrm{SM}$, et al. Plasma macrophage colony-stimulating factor and P-selectin levels in malaria-associated thrombocytopenia. Thromb Haemost. 1997;77:289-93.

22. Piguet PF, Kan CD, Vesin C. Thrombocytopenia in an animal model of malaria is associated with an increased caspase-mediated death of thrombocytes. Apoptosis. 2002;7:91-8.

23. Coelho HC, Lopes SC, Pimentel JP, Nogueira PA, Costa FT, Siqueira AM, et al. Thrombocytopenia in Plasmodium vivax malaria is related to platelets phagocytosis. PLoS One. 2013;8:e63410.

24. Raina V, Sharma A, Gujral S, Kumar R. Plasmodium vivax causing pancytopenia after allogenic blood stem cell transplantation in CML. Bone Marrow Transplant. 1998;22:205-6.

25. Carlini ME, White AC, Atmar RL. Vivax malaria complicated by adult respiratory distress syndrome. Clin Infect Dis. 1999;28:1182-3.

26. Lawn SD, Krishna S, Jarvis JN, Joet T, Macallan DC. Case reports:pernicious complications of benign tertian malaria. Trans R Soc Trop Med Hyg. 2003:97:551-3.

27. Holland B, Walker A, Collier R, Stephens J. Severe thrombocytopenia and epistaxis secondary to Plasmodium vivax infection. Internet J Infect Dis 2003;3:2.

28. Lacerda MV, Alexandre MA, Santos PD, Arcanjo AR, Alecrim WD, Alecrim MG. Idiopathic thrombocytopenic purpura due to vivax malaria in the Brazilian Amazon. Acta Trop. 2004;90:187-90.

29. Lomar AV, Vidal JE, Lomar FP, Barbas CV. Janot de Matos C, Boulos M. Acute respiratory distress syndrome due to vivax malaria: case report and literature review. Braz J Infect Dis. 2005;9:425-30.

30. Aggarwal A, Rath S. Shashiraj. Plasmodium vivax malaria presenting with severe thrombocytopenia. J Trop Pediatr. 2005;51:120-1.

31. Saleri N, Gulletta M, Matteelli A, Caligaris S, Tomasoni LR, Antonini B, et al. Acute respiratory distress syndrome in Plasmodium vivax malaria in a traveller returning from Venezuela. J Travel Med. 2006;13:112-3.
32. Baspinar O, Bayaraktaroglu Z, Karsligil T, Bayram A, Coskun Y. A rare cause of anemia and thrombocytopenia in a newborn: congenital malaria. Turk J Pediatr. 2006;48:63-5.

33. Mohin G, Gupta A. Rare case of multiorgan failure associated with Plasmodium vivax malaria. Infect Dis Clin Pract. 2007;15:209-12.

34. Kumar S, Melzer M, Dodds P, Watson J, Ord R. P. vivax malaria complicated by shock and ARDS. Scand J Infect Dis. 2007;39:255-6.

35. Kaur D, Wasir V, Gulati S, Bagga A. Unusual presentation of Plasmodium vivax malaria with severe thrombocytopenia and acute renal failure. J Trop Pediatr. 2007:53:210-2.

36. Song JY, Park CW, Jo YM, Kim JY, Yoon HJ, Kim CH, et al. Two cases of Plasmodium vivax malaria with the clinical picture resembling toxic shock. Am J Trop Med Hyg. 2007;77:609-11.

37. Lacerda MV, Hipolito JR, Passos LN. Chronic Plasmodium vivax infection in a patient with splenomegaly and severe thrombocytopenia. Rev Soc Bras Med Trop. 2008;41:522-3.

38. Thapa R, Biswas B, Mallick D, Sardar S, Modak S. Childhood Plasmodium vivax malaria with severe thrombocytopenia and bleeding manifestations. J Pediatr Hematol Oncol. 2009;31:758-9.

39. Kim SA, Kim ES, Rhee MY, Choi SI, Huh HJ, Chae SL. A case of myocarditis associated with Plasmodium vivax malaria. J Travel Med. 2009;16:138-40.

40. Harish R, Gupta S. Plasmodium vivax malaria presenting with severe thrombocytopenia, cerebral complications and hydrocephalus. Indian J Pediatr. 2009;76:551-2.

41. Lee JH, Chin HS, Chung MH, Moon YS. Case report: retinal hemorrhage in Plasmodium vivax malaria. Am J Trop Med Hyg. 2010;82:219-22.

42. Siqueira AM, Alexandre MA, Mourao MP, Santos VS, Nagahashi-Marie SK, Alecrim MG, et al. Case report: severe rhabdomyolysis caused by Plasmodium vivax malaria in the Brazilian Amazon. Am J Trop Med Hyg 2010;83:271-3.

43. Bhatia V, Bhatia J. Severe thrombocytopenia with bleeding manifestations in two children secondary to Plasmodium vivax. Platelets. 2010;21:307-9.

44. Sonkar SK, Uniyal R, Sonkar GK. Three unusual presentations of Plasmodium vivax malaria. Trop Doct. 2011;41:240-1.

45. Sharma V, Sharma A, Aggarwal A, Bhardwaj G, Aggarwal S. Acute pancreatitis in a patient with vivax malaria. JOP. 2012;13:215-6.

46. Rahman AK, Sulaiman FN. Plasmodium vivax malaria presenting as acute respiratory distress syndrome: a case report. Trop Doct. 2013;43:83-5.

47. Ahmad S, Dhar M, Bishnoi S, Shirazi N, Bhat NK. Acute myocarditis in vivax malaria: an extremely rare complication. Trop Doct. 2013;43:35-6.

48. Mehndiratta S, Rajeshwari K, Dubey AP. Multiple-organ dysfunction in a case of Plasmodium vivax malaria. J Vector Borne Dis. 2013;50:71-3.

49. Lee HJ, Baek JH, Chae MH, Joo H, Lee JS, Chung MH, et al. A case of vivax malaria complicated by adult respiratory distress syndrome and successful management with extracorporeal membrane oxygenation. Korean J Parasitol. 2013;51:551-5.

50. Gougoutsi A, Karageorgopoulos DE, Dimitriadou A, Melas N, Kranidiotis G, Voutsinas D, et al. Severe Plasmodium vivax malaria complicated with acute respiratory distress syndrome: a case associated with focal autochthonous transmission in Greece. VectorBorne Zoonotic Dis. 2014;14:378-81.

51. Pothapregada S, Kamalakannan B. Hemophagocytic syndrome in Plasmodium vivax malaria. J Vector Borne Dis. 2014;51:144-6.

52. Sharma A, Khanduri U. How benign is benign tertian malaria? J Vector Borne Dis. 2009:46:141-4.

53. George P, Alexander LM. A study on the clinical profile of complicated Plasmodium vivax mono-infections. Asian Pac J Trop Med. 2010;4:560-2.

54. Singh H, Parakh A, Basu S, Rath B. Plasmodium vivax malaria: is it actually benign? J Infect Public Health. 2011;4:91-5.

55. Gogia A, Kakar A, Byotra SP. Is benign tertian malaria actually benign? Trop Doct. 2012;42:92-3.

56. Tanwar GS, Khatri PC, Chamar CK, Sengar GS, Kochar A, et al. Thrombocytopenia in childhood malaria with special reference to $P$. vivax monoinfection: a study from Bikaner (Northwestern India). Platelets. 2012;23:211-6.

57. Naha K, Dasan S, Prabhu M. Spectrum of complications associated with Plasmodium vivax infection in a tertiary hospital in South-Western India. Asian Pac J Trop Med. 2012;5:79-82.

58. Yadav D, Chandra J, Aneja S, Kumar V, Kumar P, Dutta AK. Changing profile of severe malaria in North Indian children. Indian J Pediatr. 2012;79:483-7.

59. Sharma S, Aggarwal KC, Deswal S, Raut D, Roy N, Kapoor R. The unusual presentation of a usual organism- the changing spectrum of the clinical 
manifestations of Plasmodium vivax malaria in children:a retrospective study. J Clin Diagn Res. 2013;7:1964-7.

60. Sarkar D, Ray S, Saha M, Chakraborty A, Talukdar A. Clinico-laboratory profile of severe Plasmodium vivax malaria in a tertiary care centre in Kolkhata. Trop Parasitol. 2013;3:53-7.

61. Jain V, Agrawal A, Singh N. Malaria in a tertiary health care facility of Central India with special reference to severe vivax: implications for malaria control. Pathog Glob Health. 2013;107:299-304.

62. Singh R, Kumar S, Rana SK, Thakur B, Singh SP. A comparative study of clinical profiles of vivax and falciparum malaria in children at a tertiary care centre in Uttarakhand. J Clin Diagn Res. 2013;7:2234-7.

63. Shaik S, Memon H, Shaik A, Ahmed I, lohano B, Baird KJ. Severe disease in children hospitalized with a diagnosis of Plasmodium vivax in southeastern Pakistan. Malar J. 2012;11:144.

64. Zubairi AB, Nizami S, Raza A, Mehraj V, Rasheed AF, Ghanchi NK, et al. Severe Plasmodium vivax malaria in Pakistan. Emerg Infect Dis. 2013;19:1851-4.

65. Arboleda M, Perez MF, Fernandez D, Usuga LY, Meza M. (Clinical and laboratory profile of Plasmodium vivax malaria patients hospitalized in Apartado, Colombia) (in Spanish). Biomedica. 2012;32(Suppl):58-67.

66. Mahgoub H, Gasim GI, Musa IR, Adam I. Severe Plasmodium vivax malaria among sudanese children at New Halfa hospital, Eastern Sudan. Parasit Vectors. 2012;5:154.

67. Magalhaes BM, Siqueira AM, Alexandre MA, Souza MS, Gimaque JB, Bastos MS, et al. P. vivax malaria and dengue fever co-infection: a cross-sectional study in the Brazilian Amazon. PLoS Neglect Trop Dis. 2014;8:e3239.

68. Leal-Santos FA, Silva SB, Crepaldi NP, Nery AF, Martin TO, Alves-Junior ER, et al. Altered platelet indices as potential markers of severe and complicated malaria caused by Plasmodium vivax: a cross-sectional study. Malar J. 2013;12:462.
69. Lampah DA, Yeo TW, Malloy M, Kenangalem E, Douglas NM, Ronaldo $D$, et al. Severe malarial thrombocytopenia: a risk factor for mortality in Papua, Indonesia. J Infect Dis. 2015;211:623-34.

70. Siqueira AM, Lacerda MV, Magalhaes BM, Mourao MP, Melo GC, Alexandre MA, et al. Characterization of Plasmodium vivax-associated admissions to reference hospitals in Brazil and India. BMC Med. 2015;13:57.

71. Douglas NM, Pontororing GJ, Lampah DA, Yeo TW, Kenangalem E, Poespoprodjo JR, et al. Mortality attributable to Plasmodium vivax malaria: a clinical audit from Papua, Indonesia. BMC Med. 2014;12:217.

72. Broderick C, Nadjm B, Smith V, Blaze M, Checkley A, Chiodini PL, et al. Clinical, geographical, and temporal risk factors associated with presentation and outcome of vivax malaria imported into the United Kingdom over 27 years: observational study. BMJ. 2015;350:h1703.

73. Muhlberger N, JelinekT, Gascon J, Probst M, Zoller T, Schunk M, et al. Epidemiology and clinical features of vivax malaria imported to Europe: sentinel surveillance data from TropNetEurope. Malar J. 2004;3:5.

74. Leder K, Black J, O'Brien D, Greenwood Z, Kain KC, Schwartz E, et al. Malaria in travelers: a review of the GeoSentinel Surveillance Network. Clin Infect Dis. 2004;39:1104-12.

75. Saravu K, Rishikesh K, Kamath A, Shastry AB. Severity in Plasmodium vivax malaria claiming global vigilance and exploration- a tertiary care centrebased cohort study. Malar J. 2014;13:304.

76. Marks ME, Armstrong M, Suvan MM, Batson S, Whitty CJ, Chiodini PL, et al. Severe imported falciparum malaria among adults requiring intensive care: a retrospective study at the hospital for tropical diseases. London. BMC Infect Dis. 2013;13:118.

\section{Submit your next manuscript to BioMed Central and we will help you at every step:}

- We accept pre-submission inquiries

- Our selector tool helps you to find the most relevant journal

- We provide round the clock customer support

- Convenient online submission

- Thorough peer review

- Inclusion in PubMed and all major indexing services

- Maximum visibility for your research

Submit your manuscript at www.biomedcentral.com/submit
() Biomed Central 